\title{
Compressive Strength of Concrete Containing Milled Glass as Partial Substitute for Cement
}

\author{
Raheem S.B, Oladiran G. F, Oke D. A.
}

Department Of Civil Engineering, Faculty of Engineering, The Polytechnic Ibadan. Ibadan, Nigeria.

\begin{abstract}
This work reports the outcome of an experiment carried out by using milled glass (MG) of varying percentages $(20 \%, 40 \%$ and $60 \%$ by weight)of cement in concrete making. MG was sourced for and milled to required fineness. The concrete was batched with mix ratio of $1: 2: 4$. Concrete Cube specimens produced were allowed to cure for 7-28 days and compressive strength, slump and setting time tests were carried out and were compared with those of conventional concrete $(0 \% \mathrm{MG})$. Results obtained showed that compressive strength of the concrete increased with increase in length of curing age, but decreased as the percentage of MG increased. However, the strength still remained in the allowable range of workability for concrete in line with British standard. MG replacement of $20 \%$ was found to be the most suitable mix considering the strength and safe use of the concrete. It was concluded that MG replacement of $20 \%$ showed no significant loss in strength compared to the control sample and is stable and could be acceptable in most concrete. At the long run. Waste glass that currently constitutes waste concern in built environment in Nigeria can best be managed through alternative use in concrete production.
\end{abstract}

Keyword-Compressive, Milled Glass, Workability, Pozzolanic.

\section{INTRODUCTION}

The interest of the construction community in using waste or recycled materials in concrete is increasing because of the emphasis placed on sustainable construction, the waste glass from in and around the small shops is packed as a waste and disposed as landfill.

Glass is an inert material which could be recycled and used many times without changing its chemical property (AiminXu and Ahmad shayam, 2004). Besides using waste glass as cullet in glass manufacturing, waste glass is crushed into specified sizes for use as aggregate in various applications such as water filtration, grit plastering, sand cover for sport turf and sand replacement in concrete (Carpenter, A.J. and Cramer, C.M, 1999). Since the demand in the concrete manufacturing is increasing day by day, the utilization of river sand as fine aggregate leads to exploitation of natural resources, lowering of water table, sinking of the bridge piers, etc. as a common treat. Attempts has been made in using crushed glass as fine aggregate in the replacement of river sand (Chi sing lam, chi sun poon and Dixon chan,2007). The crushed glass was also used as coarse aggregate in concrete production but due to its flat and elongated nature which enhances the decrease in the workability and attributed the drop in compressive strength (Christopercheeseman ,2011) Glass is amorphous material with high silica content, thus making it potentially pozzolanic when particle size is less than $75 \mu \mathrm{m}$ (Federio. L.M and Chidiac S.E, 2001, Jin.W, Meyer.C, and Baxter.S, 2000). Studies have shown that finely ground glass does not contribute to alkali-silica reaction. In the recent, various attempts and research have been made to use ground glass as a replacement in conventional ingredients in concrete production as a part of green house management. A major concern regarding the use of glass in concrete is the chemical reaction that takes place between the silica-rich glass particle and the alkali in pore solution of concrete, which is called Alkali-Silicate reaction, can be very detrimental to the stability of concrete, unless appropriate precautions are taken to minimize its effects. ASR can be prevented or reduced by adding mineral admixtures in the concrete mixture, common mineral admixtures used to minimize ASR are pulverized fuel ash (PFA), silica fume(SF) and metkaolin (MK).A number of studies have proven the suppressing ability of these materials on ASR. A high amount of waste glass as aggregate is known to decrease the concrete unit weight (Christopher cheeseman, 2011, Mageswari. L.M and B.Vidivelli, 2010). The fact that glass has high silica content has led to laboratory studies on its feasibility as a raw material in cement manufacture. The use of finely divided glass powder as a cement replacement material has yielded positive results (MalekBatayneh, Iqbal Marie, Ibrahim Asi, 2007), Optimal dosage range of this glass powder is chosen based on cement paste studies. International Journal of Emerging Technology and Advanced EngineeringWebsite:www.ijetae.com (ISSN 2250-2459,ISO 9001:2008 Certified Journal, Volume 3, Issue 2, February 2013) 154Selected properties of the glass 
powder modified mixtures are compared with the properties

of conventional concrete (C.Meyer, S.Baxter and W.Jin,1996,Narayanan Neithalath and Nathan Schwarz,2009). The ultimate aim of this work is to ascertain the performance of concretes containing glass powder and compare it with the performance of conventional concretes. Waste glass is often less expensive and readily available than conventional current. By replacing a portion of conventional cement with milled glass, the overall cost of the cementitous composition can be reduced thus reducing the consumption of Portland cement and consuming excess calcium hydroxide.

Utilization of such manufacturing waste serve as an effective method of minimizing waste generation and also finding alternative to conventional building material whose high cost has resulted to avoidable housing incidence, hence this research seek to improve the quality of the environment by saving energy, management of waste, conservation of the natural resources and ensuring sustainability in built environment.

\subsection{Chemical Composition of Cement and MG}

The chemical composition of both the cement and MG is presented in Table. 1 It is observed that the dominant oxide in the cement and $\mathrm{MG}$ are $\mathrm{CaO}$ and $\mathrm{SiO}_{2}$ respectively. $\mathrm{CaO}$ is the main source of binding and hardening compound in cement, when reacted with water (hydration reaction), which is very low in MG. But, the $\mathrm{SiO}_{2}$ in $\mathrm{MG}$ reacts with $\mathrm{Ca}(\mathrm{OH})_{2}$ (by product of cement hydration) to produce more binding property (Pozzolanic reaction). The advantage of reduction in the consumption of cement leading to reduction in the greenhouse effects of cement usage is being exploited by the use of pozzolan in concrete production.

\section{MATERIALS AND METHODS}

I. Cement, water and Aggregates: The cement used in this study was Ordinary Portland Cement with brand name Elephant. The properties of the cement are presented in Table 1. Fine aggregate used was river sand while crushed granite of maximum nominal particle size of $19 \mathrm{~mm}$ was used as coarse aggregate. The grading for the aggregates was done according to BS 1377 Parts 1 and 2.

II. Milled Glass: Waste glasses were collected from glass cutters shop at OmowumiOlorunsogo, Ibadan Oyo State, Nigeria. The milled glass was produced by grinding the crushed glass with grinding machine before it was sieved, using $150 \mu \mathrm{m}$ sieve size to produce powdery form.

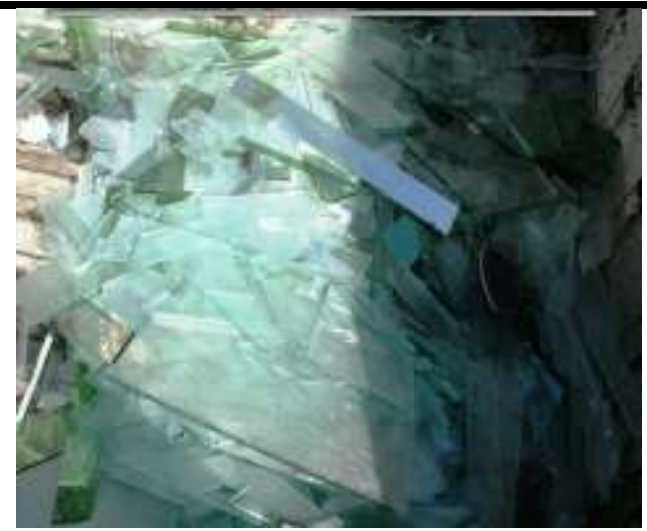

Fig. 1: Waste Glass

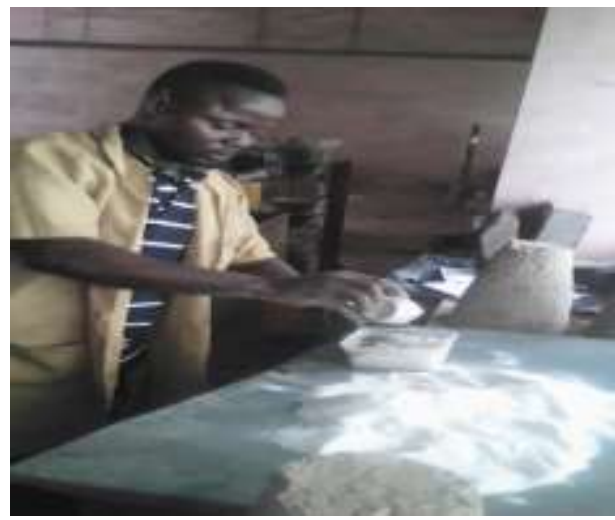

Fig.2: Milled Glass

\subsection{Sample Preparation and Tests}

\section{Sample Preparation}

The concrete investigated was of mix ratio 1:2:4 (cement and grounded glass powder: sand: granite) with varied water/binder ratios of $0.55,0.60,0.65$ and 0.70 . The cement was replaced with milled glass at $0 \%, 20 \%, 40 \%$, and $60 \%$ by weight of cement as binder and mixed with sand and granite as fine and coarse aggregates respectively. Batching of the concrete mix was by weight.

\section{Workability Test}

Workability is the property of freshly mixed concrete that determines the ease with which it can be properly mixed,placed, consolidated and finished without segregation. The workability of fresh concrete was measured by means of the conventional slump test as per BS 1881: 102. Before the fresh concrete was cast into moulds, the slump value of the fresh concrete was measured using slump cone. In this project work, the slump value of fresh concrete was maintained in the range of $30 \mathrm{~mm}$ to $50 \mathrm{~mm}$. 


\section{Setting time}

The setting time of cement is the result of the hydration of Portland cement; produce microscopic mineral products that link adjacent cement grains to each other. As hydration progresses, each cement grain is bound more tightly together so that it becomes more difficult for outside force to deform the concrete. The initial and final setting times of $\mathrm{OPC} / \mathrm{MG}$ concrete mixes and the trend of variation of setting times shows an increase of both setting times with the increase of MG content. As the MG content is increased from $0 \%$ to $60 \%$, the initial setting time was found to increase from 95 minutes to 140 minutes and the final setting time increased from 145 minutes to 210 minutes.

\section{Compressive Strength test}

Compressive strength of concrete determines to a great extent the ability of structure to withstand the load imposed on it. The concrete cubes samples for $0 \%, 20 \%, 40 \%$, and $60 \%$ for 7 days were removed from the curing tank and were allowed to dry for 24 hours before they were crushed with use of a Universal compressive strength test machine at the civil engineering soil laboratory, The Polytechnic, Ibadan. The cubes were firstly weighed with the use of a weighing balance to determine the weight of the cubes, and the cubes were placed at the compressive chamber in the Universal test machine and loads were applied on the cubes. The crushing loads were obtained when the cube specimens cracked, the crushing loads obtained was then divided by the area of the cubes to determine the compressive strengths. This process was repeated for 7, 14, 21 and 28days and the values gotten were reported in figure 1 .
The compressive strength was calculated by dividing the load by the cross-sectional area of the specimen. Compressive strength $=$. (crushing load)/(cross sectional area

Where Crushing load=value of load obtained from the compressive testing machine at specimen failure Cross sectional area $=150 \mathrm{mmx} 150 \mathrm{~mm} \times 150 \mathrm{~mm}$

\section{RESULT AND DISCUSSION}

The compressive strength test on both conventional and glass blended concrete was performed on universal compressive testing machine. Totally 32 numbers of cube specimens of size $150 \mathrm{~mm} \times 150 \mathrm{mmx} 150 \mathrm{~mm}$, were cast and tested for the compressive strength at the age of $7,14,21$, 28 days. The result obtained showed that the compressive strength decreases as the percentage of MG increases, also the compressive strength of concrete increases as the curingage increases which shows that the crushing strength increases as the age increases. For normal concrete, $0 \%$ MG, the compressive strength at 28-day was $24.6 \mathrm{~N} / \mathrm{mm}^{2}$ while that of 20,40 and $60 \%$ were $17.35,12.90$ and $7.01 \mathrm{~N} / \mathrm{mm}^{2}$ respectively. With the exception of $20 \% \mathrm{MG}$ replacement of cement, it was observed that the difference in strength between the normal concrete and MG blended concrete reduces progressively with age. This was an indication that $\mathrm{MG}$ has potential to contribute to late strength development when not more than $20 \%$ by weight of cement is used. It could be suggested that MG possesses pozzolanic characteristics.

Table.1: Chemical composition of cement and milled waste glass (MG).

\begin{tabular}{lccccccccccc}
\hline Chemical composition & $\mathrm{SiO}_{2}$ & $\mathrm{Al}_{2} \mathrm{O}_{3}$ & $\mathrm{Fe}_{2} \mathrm{O}_{3}$ & $\mathrm{CaO}$ & $\mathrm{MgO}$ & $\mathrm{Na}_{2} \mathrm{O}$ & $\mathrm{K}_{2} \mathrm{O}$ & $\mathrm{SO}_{3}$ & $\mathrm{TiO}_{2}$ \\
\hline Cement & 20.80 & 3.10 & 2.50 & 63.61 & 1.39 & 0.13 & 0.61 & 1.94 & - \\
MWG & 71.48 & 1.70 & 0.37 & 11.45 & 1.65 & 13.36 & 0.48 & 0.27 & 0.04 \\
\hline
\end{tabular}

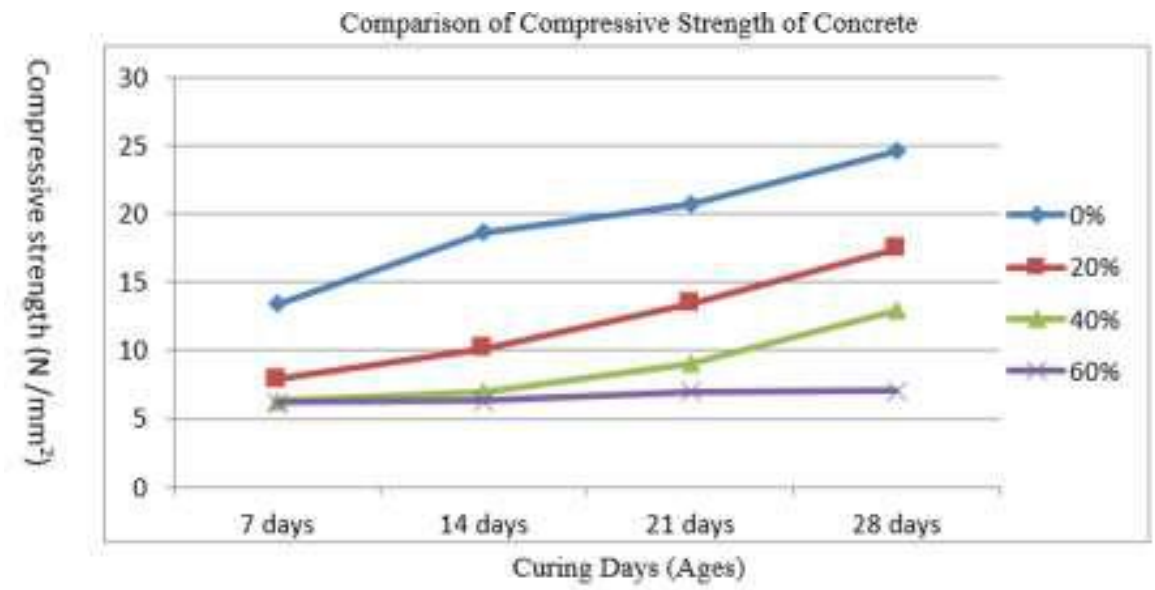

Fig.1: Comparison between compressive strength of concrete at 0\%, 20\%, 40\% and 60\% MG. 


\section{CONCLUSION}

This research was carried out to determine the feasibility of using milled glass to partially replace cement as an alternative binder in concrete production. For normal concrete with $0 \% \mathrm{MG}$, the compressive strength at 28 day is $24.6 \mathrm{~N} / \mathrm{mm}^{2}$ while that of 20,40 and $60 \%$ are $17.35,12.90$ and $7.01 \mathrm{~N} / \mathrm{mm}^{2}$ respectively representing a decrease of $7.25, \quad 11.7$ and $17.59 \%$ respectively. The following conclusions are drawn:

1. Compressive strengths increases with age but reduces with increase in MG content in the mix especially when more than $20 \%$ MGwas used.

2. As MG content increases, water-binder (w/b) to achieve workable concrete also increases. It is suggested that an optimum w/b ratio of 0.7 may be appropriate

3. Concrete made from cement (OPC) - milled glass powder possesses relative low compressive strength.

4. MG replacement of $20 \%$ in concrete with OPC showed no significant loss in strength compared to the control sample.

\section{REFERENCES}

[1] AiminXu and Ahmad shayam, "Value - added utilization of waste glass in concrete", Cement and concrete research, vol.34,81-89,2004.

[2] Archibald J.F., Chew J.L. and Lausch, P. (1997). -Paste backfill consolidation using ground waste glass as a portland cement binder replacementll. Canadian institute of Mining.Metallurgy and Petroleum Journal Annual General Meeting Technical Presentation, Vancouver, British Columbia.

[3] American Society of Testing and Materials.(ASTM C618).- Standard Specification for Coal ash and Raw or Calcined Natural Pozzolan for Use in Concrete.

[4] Balachandra, Anagi. (2010). - Value-added Use of Milled Waste Glass as a Supplementary Cementitious Material in Environmentally Friendly and EnergyEfficient Concrete Building Constructionll, Small Business Innovation Research (SBIR), Phase II.

[5] Carpenter,A.J. and Cramer,C.M, " Mitigation of ASR in pavement patch concrete that incorporates highly reactive fine aggregate", Transportation Research Record 1668, Paper No.99-1087,pp.60$67,1999$.

[6] Chi sing lam, chi sun poon and Dixon chan, "Enhancingthe performance of pre - cast concrete blocks by incorporating waste glass - ASR consideration", Cement and concrete composites, vol: 29pp, 616-625,2007.
[7] Christopher cheeseman, "Production of sintered light weight aggregate using waste ash and other industrial residues", Belgium, 2011.

[8] Cordeiro G.C., Toledo Filho R.D., Fairbairn E.M.R., Tavares L.M.M. (2009) -Pozzolanic activity and filler effect of sugarcane bagasse ash in Portland cement and lime mortarl, Cement and Concrete Composites 30, 410-418

[9] Federio.L.M and Chidiac S.E, "Waste glass as a supplementarycementitious material in concrete Critical review of treatment methods", Cement and Concrete Composites, vol, 31,606-610, 2001.

[10] Mageswari.L.M and B.Vidivelli, "The use of Sheet Glass Powder asFine Aggregate Replacement in Concrete", the open Civil Engineering Journal, vol: 4, 65-71, 2010.

[11] MalekBatayneh, Iqbal Marie, Ibrahim Asi, "Use of Selected wasteMaterials in Concrete Mixes", Waste Management, vol. 27, 2007.

[12] C.Meyer, S.Baxter and W.Jin, "alkali - Aggregate Reaction in Concrete with waste Glass as Aggregate", Proceedings of the $4^{\text {th }}$ Materials Engineering Conference: Materials for the new millennium, ASCE, Reston, V.A, pp.1388-1397, 1996.

[13] Narayanan Neithalath and Nathan Schwarz, "Properties of Cast - in - Place Concrete and Precast Concrete Blocks Incorporating Waste Glass Powder", the open Construction and Building Technology Journal, vol: 3, 42-51, 2009. 